\title{
CONTRIBUTION TO THE STUDY OF THE PHENOMENON OF SENILITY IN THE RAT OVARY AND THE RELATION BETWEEN THE OVARY AND THE GANGLION CERVICALE UTERI OF THE RAT
}

\author{
OSAMU TAKAHASHI and KAZUYO SHIMAI \\ Department of Anatomy, School of Medicine, Keio University, \\ Tokyo, Japan
}

(Received for publication November 26, 1962)

\section{INTRODUCTION}

On the relation between the ovary and ganglion cervicale uteri there are few reports. Only Blotevogel (1927), Hofbauer (1950), Gasparini (1952) and Lehmann et Stange (1953) have histologically investigated on the ganglion cervicale uteri during the pregnant period. Takahashi (1960) has refered to the relationship between the ovary and the nerve cells of the ganglion cervicale uteri, in his report on the vacuoles which arise in the cells of the ganglion cervicale uteri of rats and mice. That is, there are some relations between the function of the ovary and the phenomenon assembling the neurosecretion which is observed in the cells of the ganglion cervicale uteri. Furthermore, Takahashi and Shimai (1961) have observed, in their report on the phenomenon of the senility in the ganglion cervicale uteri of the rats, that the ganglion cervicale uteri of the rats of 730 to 760 days after birth shows the phenomena of senility. In the present study the authors will describe the relationship between the ovary and the ganglion cervicale uteri, by comparing with the senile condition of the ovary and that of the ganglion cervicale uteri.

\section{MATERIAL AND METHODS}

Eight healthy female rats of 700 to 760 days after birth, which were bred under common condition were employed as the material and similarly three healthy adult female rats of about 300 days after birth were used. After the rats underwent ventrotomy under ether anaesthesia, the ovary and cervical portion of the uterus with enough parametorium were taken out. At the same time the pancreas and parotis glands were obtained. The tissues were fixed with Bouin's solution and with $96 \%$ alcohol, embedded in paraffin and cut serially

* To Prof. Dr. T. Ogawa for his Sixieth Birthday. 
in 5-10 micra of thickness. The sections were stained with Nissl staining, hematoxylin-eosin staining, Azan staining and Gomori's chrome alum-hematoxylin phloxine staining (Gomori 1941).

\section{ORIGINAL FINDINGS}

The female rats of 700 to 760 days after birth, which were bred under the common condition, weigh 200 to $250 \mathrm{~g}$, respectively, and their subcutaneous fat (adipose tissue) is well developed. But their organs generally show a tendency to contract and this phenomenon is very remarkable in the parotid gland, ovary and uterus. In the parotid glands of the rats, glandular cells are contracted, or it is noticed that the glandular cells were vanished and that portions were filled with the adipose tissue. In the straited portion the epithelial cells are flattened and ductular lumen are enlarged.

In the pancreas of the rats, adipose degeneration of acinal tissue, karyopycnosis of the glandular cells, and abnormal hypertrophy of Langerhans island, these are called phenomena of senility, are recognized (Takahashi and Shimai 1961).

In the ganglion cervicale uteri of these rats, the connective tissue is increased and the formation of slits is recognizable in the ganglion tissue. Moreover the stainability of the ganglion cells become low and that of the Nissl granules also is weak. On the occurrence of the vacuoles in the cells of the ganglion cervicale uteri, it is somewhat higher in frequency than that in the castrated rats but lower than those in the adult rats, pregnant rats and the rats given follicle hormone injection (Takahashi 1960, Takahashi and Shimai 1961).

In general the ovary of the rats is macroscopically observed shrinked, namely the surface of the ovary is remarkably rough. Microscopically, the occurrence of the follicles is extremely decreased and the cortical substance (cortex) is occupied with a good number of the Iutein body, especially obturative lutein bodies are increased. Increase of the connective tissue and the fibroformation of the lutein body is also remarkable.

These findings mentioned above, are recognized especially in the rats of 760 days after birth as it is described in general books, the desquamation of the follicle cells in the follicles or formation of the cyste are recognized. However a few follicles which are in the course of various development are recognized and Graafian follicles are also noticed.

\section{DISCUSSION}

The parotid glands of the female rats of 700 to 760 days after birth, which 
are bred under common environment, show disappearance of the glandular cells, increase of the adipose tissue in compensation for the cells, turning the epithelial cells at the striated portion into flat ones, and enlargement of the ductular lumen. In the lobule of the pancreas, adipose degeneration of the acinar tissue and abnormal swelling of the Langerhans island are noticeable. Namely, these data show the phenomena of senility in the rats (Takahashi and Shimai 1961). In the ovary of the rats, the number of the follicles is very small and the lutein bodies, especially, obturative lutein bodies are increased. Though it is small, the desquamation of the follicle cells in the follicles is recognized, on the other hand a few follicles which are in the course of development are found from these findings in the ovary of the rats mentioned above, it is thought, that phenomena of the senility in the ovary of the rats are already recognizable but they are imcomplete.

On the relation between the ovary and the ganglion cervicale uteri, Blotevogel (1927) and Hofbauer (1950) have insisted that the stainability of the cells of the ganglion cervicale uteri is increased at the pregnant time. Gasparini (1952) has reported that these cells show swelling during the pregnant period, and also according to Lehmann and Stange (1953) the occurrence of the vacuoles in the cells of the ganglion cervicale uteri is increased, and the formation of the vacuoles is a part of the neurosecretory phenomena. These results mentioned above, are obtained from the pregnant subjects. Recently one of the authors has described that the vacuoles which arise in the cells of the ganglion cervicale uteri of the rats have something to do with the neurosecretory phenomena (Takahashi 1960). In that author's report, he investigated that, as table 1 in that author's paper will show, in the young rats, vacuoles are not found in the cells of the ganglion cervicale uteri, but in the adult rats vacuoles are at the first time recognizable in the cells. In the pregnant rats the vacuoles are increase and when the watersoluble follicle hormone were injected, these vacuoles increased in the maximum largest. On the other hand, in the castrated ones, no vacuoles are found. These facts suggest some relations between the ovary and the ganglion cervicale uteri.

As described before, the ovary of the rats of 700 to 760 days after birth shows the phenomena of the senility but these phenomena seem to be yet incomplete. On the other hand, in the ganglion cervicale uteri of the rats, such phenomena of senility as increase of the connective tissue, lowering of the stainability of the ganglion cells, are recognizable. The vacuoles in the cells of the ganglion cervicale uteri are certainly decreased, but the occurrence of the vacuoles is yet continual. Namely, there is a reverse relation between the senile extent 
of the ovary and the occurrence of the vacuoles in the cells of the ganglion cervicale uteri accordingly it may be thought, that ovary and the ganglion cervicale uteri have some relation.

\section{CONCLUSION}

1. In regard to the phenomena of the senility in the ovary, increase of the connective tissue fibers, decrease of the follicles in number and increase of lutein bodies, especially obturative ones are noticeable.

2. There are some relation between the phenomena of senility in the ovary and the secretory phenomena in the cells of the ganglion cervicale uteri, namely between both phenomena some functional relation is recognizable.

\section{REFERENCES}

1. Blotevogel, W.: Sympathicus and Sexualzyklus. Versuch einen Histolo-physilogie des Ganglion cervicale uteri. Z. mikrosk,-anat. Forsch. 10: 141-169, 1927.

2. Gasparini, F.: 1952 (cited from K. A. Reisner: Die Nervenzelle. Handb. d. mikr. Anat. d. Menschen, IV/4, Springer-Verlag, Berlin, 1959).

3. Gomori, G.: Observations with differential stains on human islets of Langerhans. Amer. J. Path. 17: 395-406, 1941.

4. Hofbauer, J.: 1950 (cited from H. J. Lehmann and H. H. Stange 1953).

5. Lehmann, H. J., and H. H. Stange: Über das Vorkommen vakuolenhaltiger Ganglienzellen im Ganglion cervicale uteri trächtiger und nicht-trächtiger Ratten. Z. Zellforsch. 38: 230-236, 1953.

6. Takahashi, O.: On the formation of vacuoles in the nerve cells of the ganglion cervicalis uteri on the rat and mouse. Okajimas Fol. anat. jap. 34: 189-205, 1960.

7. Takahashi, O., and K. Shimai.: Study on the ganglion cervicalis uteri of the aged rats. Okajimas Fol. anat. jap. 36: 455-463, 1961.

\section{EXPLANATION OF FIGURES}

Fig. 1. Mature ovary. $\times 34$.

Fig. 2-3. Increase of the fibers and formation of the space of on the ganglion cervicale uteri. 748 days old rat. Fig. $2 . \times 80$, Fig. $3 . \times 160$.

Fig. 4. Flattened surface of the ovary, increase of the lutein bodies and decrease of the follicles. 748 days old rat. $\times 34$. 


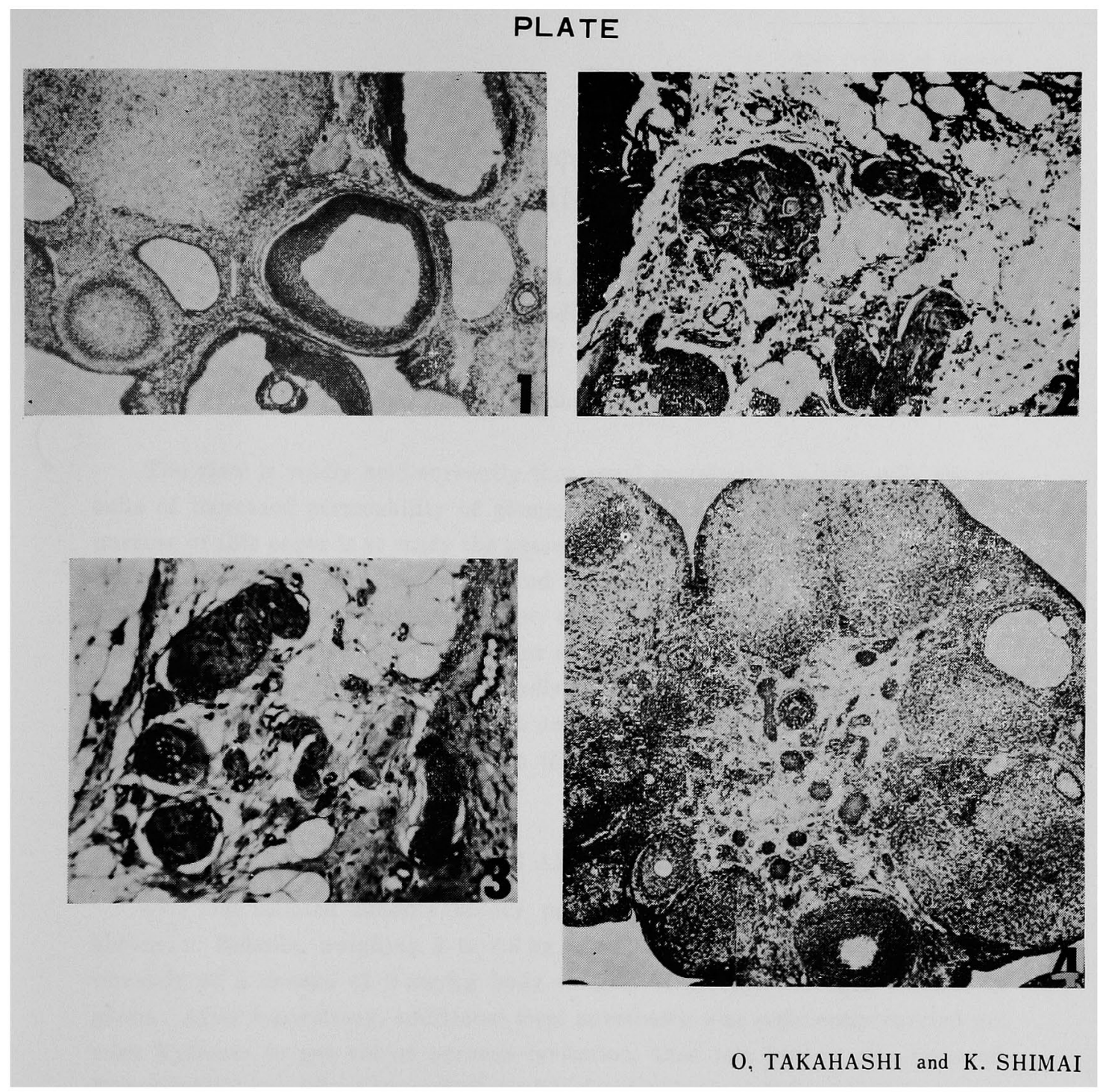

